\title{
Fast and Sensitive Chiral Analysis of Amphetamines and Cathinones in Equine Urine and Plasma Using Liquid Chromatography Tandem Mass Spectrometry
}

\author{
Caroline C. Wang, Petra Hartmann-Fischbach, Tim R. Krueger, Alisha Lester, \\ Aaron Simonson, Terry L. Wells, Max O. Wolk, Nick J. Hidlay \\ Industrial Laboratories, Wheat Ridge, USA \\ Email: carolinewang66@yahoo.com
}

Received 21 October 2015; accepted 1 December 2015; published 4 December 2015

Copyright (C) 2015 by authors and Scientific Research Publishing Inc.

This work is licensed under the Creative Commons Attribution International License (CC BY). http://creativecommons.org/licenses/by/4.0/

(c) (i) Open Access

\begin{abstract}
A simple, rapid, sensitive and reproducible method for enantiomer analysis of methamphetamine, amphetamine, cathinone and methcathinone was developed and validated. The compounds were extracted from equine plasma and urine using a fast liquid-liquid extraction procedure. Only one milliliter plasma and one hundred microliter urine sample is needed for analysis. The extraction procedure had good recovery $(>70 \%)$ and the matrix effect was negligible. Enantiomer differentiation and confirmation were achieved using liquid chromatography with chiral stationary phase and mass spectrometry detection. The method demonstrated excellent reproducibility with intraday and inter-day precision of lower than $5 \%$. The lower limits of detection for all of the compounds studied here were at low $\mathrm{pg} / \mathrm{mL}$ level for both plasma and urine. This is the first report of the analysis of four chiral compounds in equine plasma and urine. Routine application was demonstrated for (S)- and (R)-enantiomer differentiation.
\end{abstract}

\section{Keywords}

Amphetamines and Cathinones, Equine Plasma and Urine, Chiral Analysis, Liquid Chromatography Tandem Mass Spectrometry 


\section{Introduction}

Methamphetamine, amphetamine, cathinone and methcathinone are powerful central nerve system (CNS) stimulants and are abused in many countries [1]-[8]. According to Uniform Classification Guidelines for Foreign Substances and Recommended Penalties and Model Rules from Association and Racing Commissioner International (RCI), methamphetamine, amphetamine, cathinone and methcathinone are all Class I drugs based on their ability to influence the outcome of a horse race. Class A Penalty will be imposed if any of these drugs are confirmed present at any level in post-race equine urine or plasma.

Amphetamine is a metabolite of methamphetamine [8] [9]. Cathinone and methcathinone both have a $\beta$-keto group and they are structurally close to amphetamine. These four compounds all contain a chiral center and have $\mathrm{S}$ and $\mathrm{R}$ enantiomers. The two enantiomers are non-superimposable mirror images of each other. In animal studies, the CNS stimulant activities increase in the order of (S)-amphetamine, (S)-cathinone, (S)-metham-phetamine and (S)-methcathinone [1]. Research results showed that the S-enantiomers of the four compounds demonstrated more CNS stimulant potency than the corresponding R-enantiomers due to the binding affinity differences to their receptor sites [9]-[13]. In the United States, (R)-methamphetamine is available in some over-thecounter nasal decongestant products, such as Vicks-Vapor inhaler and its generic equivalents. The illicitly manufactured methamphetamine consists mainly the S-enantiomer. Unambiguous identification of enantiomers can be extremely useful in clinical, forensic, and toxicological applications to distinguish illicit consumption, origin and the metabolism of the target compound [8]-[13].

Over the years, gas chromatography (GC), capillary electrophoresis (CE), and high performance liquid chromatography (HPLC) have been used for enantiomer analysis [5] [8] [9] [12]-[25]. Chiral separations can be classified into three categories [15]. The first one is pre-column derivatization with a chiral derivatization reagent to generate diastereomers; the second one involves adding a chiral agent to the mobile phase to form adducts with the enantiomers; and the third one is a direct method using chiral stationary phase[20] [25]. GC methods involve complicated and time consuming pre-column derivatization steps [3] [8] [12]-[14]. Liquid chromatography mass spectrometry (LC-MS) has gained more and more popularity for drug analysis because it is generally faster, easy to use and has better sensitivity and specificity [22] [23]. Chiral additive in mobile phase is usually not compatible for mass spectrometry detection [20] [25]. Direct chiral separation using chiral stationary phase without previous derivatization is a convenient choice for LC-MS analysis. The published methods with this approach had poor sensitivity and very long acquisition time [17] [18] [23]. We are presenting a fast and sensitive liquid chromatography tandem mass spectrometry (LC-MS/MS) chiral analysis method that can be used for the differentiation of the enantiomers of four compounds after an easy extraction from equine plasma and urine. To the author's knowledge, this is the first report of this kind in racing industry.

\section{Experimental}

\subsection{Chemicals \& Reagents}

S(+)-Methamphetamine, R(-)-Methamphetamine, S(+)-Amphetamine, R(-)-Amphetamine, S(-)-Cathinone, $\mathrm{R}(+)-$ Cathinone, $\mathrm{S}(-)$-Methcathinone, and $\mathrm{R}(+)$-Methcathinone were purchased from Cerilliant (Round Rock, TX, USA). Formic acid and ammonium formate were from Sigma-Aldrich (St. Louis, MO, USA). Potassium hydroxide (KOH), Methyl-tert butyl ether (MTBE), and LC-MS grademethanol and acetonitrile were obtained from Spectrum Chemical (Gardena, CA, USA).

All of the stock solutions were prepared at $1 \mathrm{mg} / \mathrm{mL}$ in methanol. The working standard solutions $(1 \mu \mathrm{g} / \mathrm{mL}$, $10 \mathrm{ng} / \mathrm{mL}$ and $1 \mathrm{ng} / \mathrm{mL}$ ) were prepared by serial dilution of the eight stock solutions with acetonitrile. All solutions were stored at $-20^{\circ} \mathrm{C}$ in tightly sealed glass bottles. All drug standard solutions were allowed to equilibrate to room temperature for at least 30 minutes before use. No internal standard was used since it is a confirmation analysis and quantitation is not necessary.

\subsection{Sample Preparations}

Liquid-liquid extraction was used to extract cathinones and amphetamines from equine plasma and urine. Urine and plasma samples were prepared using similar procedures. The extraction was conducted using $1 \mathrm{~mL}$ of plasma or $0.1 \mathrm{~mL}$ urine mixed with $1 \mathrm{~mL}$ water. The mixture was then mixed thoroughly with $50 \mu \mathrm{L} 1 \mathrm{M} \mathrm{KOH}$ to ensure that the samples were basic. Five milliliter of MTBE was added for liquid-liquid extraction. The tubes 
were gently shaken for 10 minutes on a rotorack and centrifuged at 3000 revolution per minute (RPM) for 10 minutes. The top organic layer was transferred to Pyrex disposable glass test tubes $(16 \times 100 \mathrm{~mm})$, and the contents were dried at $40^{\circ} \mathrm{C}$ under nitrogen in a turbovap evaporator. The extracts were reconstituted with $100 \mu \mathrm{L}$ solvent (water and methanol, volume ratio of 1:1) and transferred to polypropylene autosampler vials. For each LC-MS/MS analysis, ten microliters of the dissolved extract was used.

\subsection{LC-MS/MS Conditions}

The LC-MS/MS system comprised a Shimadzu liquid chromatography system and an AB Sciex 4000 Qtrap mass spectrometer. The LC system consisted of LC-20ADXR pumps, a SIL-20ACXR auto-sampler, a DGU20A5 degasser and a CTO-20A column oven (Shimadzu Scientific Instruments, Columbia, MD, USA). Analyte separation was performed on an Astec Chirobiotic V2 column $(2.1 \times 150 \mathrm{~mm}, 5$ micron particle size $)$ from Sigma (St. Louis, MO, USA). Column oven temperature was maintained at $25^{\circ} \mathrm{C}$. The mobile phase was a mixture of methanol and $50 \mathrm{mM}$ ammonium formate/0.01\% formic acid in LC-MS grade water (95/5, v/v). The isocratic total flow was $0.45 \mathrm{~mL} / \mathrm{min}$ and the total analysis time was only6 minutes.

Qtrap 4000 (AB Sciex, Foster City, CA, USA) was used for mass spectrometry analysis. Positive ionspray voltage was set at 4000 volts. Ultra-pure nitrogen was used for ion source solvent evaporation and vacuum control. Gas 1, Gas 2, and curtain gas settings were 65, 45 and 40 psi, respectively. The ion source temperature was set at $400^{\circ} \mathrm{C}$. Multiple-reaction-monitoring (MRM) was used for analysis due to its high sensitivity and specificity. The neat standards were infused using a syringe pump for optimization of ion source parameters. The quantifying ion is the most intense ion among all of the MRM transitions for one compound. The chromatographic peak areas of the quantifying ions are used for calculations of recovery, precision and matrix effect in the validation process. The other ions are qualifying ions that are used for ion chromatographic peak area ratio calculations. The quantifying ions, qualifying ions and the corresponding settings for declustering potential (DP), entrance potential (EP), collision energy (CE) and collision cell exit potential (CXP) for each compounds are listed in Table 1.

Table 1. MRM acquisition ions used and the corresponding electronic parameters for methamphetamine, amphetamine, cathinone and methcathinone.

\begin{tabular}{|c|c|c|c|c|c|}
\hline & & DP (volts) & EP (volts) & CE (volts) & CXP (volts) \\
\hline \multicolumn{6}{|c|}{ Methamphetamine } \\
\hline Quantifying ion & 91 & 44 & 9 & 26 & 7.5 \\
\hline Qualifying ion & 119 & 44 & 9 & 16 & 7.5 \\
\hline Qualifying ion & 65 & 44 & 9 & 56 & 11 \\
\hline \multicolumn{6}{|c|}{ Amphetamine } \\
\hline Quantifying ion & 91 & 35 & 9 & 26 & 7.5 \\
\hline Qualifying ion & 119 & 35 & 9 & 13 & 3.5 \\
\hline Qualifying ion & 65 & 35 & 9 & 52 & 9 \\
\hline \multicolumn{6}{|c|}{ Cathinone } \\
\hline Quantifying ion & 117 & 39 & 10 & 34 & 9 \\
\hline Qualifying ion & 105 & 39 & 10 & 26 & 11 \\
\hline Qualifying ion & 89 & 39 & 10 & 59 & 7 \\
\hline \multicolumn{6}{|c|}{ Methcathinone } \\
\hline Quantifying ion & 131 & 49 & 14 & 29 & 10 \\
\hline Qualifying ion & 130 & 49 & 14 & 44 & 10 \\
\hline Qualifying ion & 105 & 49 & 14 & 33 & 8 \\
\hline
\end{tabular}




\subsection{Method Validation}

Validation of this liquid-liquid extraction LC-MS/MS acquisition method was performed by checking specificity, extraction recovery, matrix effect, intra-day and inter-day precision, and limit of detection. Methamphetamine, amphetamine, cathinone and methcathinone are all RCI class 1 drugs, and positive confirmation of these drugs at any level in equine plasma or urine would be a violation. Since quantification is not necessary, the limit of quantification or linearity range was not assessed. Because each of the four compounds studied here has $\mathrm{S}$ and $\mathrm{R}$ enantiomers, eight analytes were evaluated.

Endogenous compounds and other matrix interferences could produce a false positive for analytes of interest. The method specificity was demonstrated by analysis of six different lots of blank equine plasma or urine samples. Each chromatogram was checked for peaks that might interfere with the detection of the eight analytes.

Extraction recovery was evaluated in three replicates. Plasma samples at concentration $0.1 \mathrm{ng} / \mathrm{mL}$ and urine samples at $1 \mathrm{ng} / \mathrm{mL}$ were extracted. Three blank plasma and urine samples were extracted in the same batch. After extraction, the blank plasma or urine extracts were spiked with the eight analytes to the corresponding concentration of $0.1 \mathrm{ng} / \mathrm{mL}$ (plasma) or $1 \mathrm{ng} / \mathrm{mL}$ (urine). Recovery was determined by comparing the average chromatographic peak areas between the samples spiked with the drug standards before and after extractions.

Ionization suppression or enhancement in electrospray ionization is usually from matrix effect. Triplicate samples at concentrations of $0.1 \mathrm{ng} / \mathrm{mL}$ (plasma) and $1 \mathrm{ng} / \mathrm{mL}$ (urine) were extracted and analyzed by this LCMS/MS method. The same experiment was performed using deionized water. The plasma or urine matrix effect was calculated by comparing average chromatographic peak areas of the quantifying ions in plasma or urine with those in water. If the plasma or urine signal was stronger than that of water, it showed matrix enhancement, while a lower value indicated matrix suppression.

Intra-day precision was evaluated by analyzing six replicate plasma or urine samples at concentration of 0.1 $\mathrm{ng} / \mathrm{mL}$ (plasma) or $1 \mathrm{ng} / \mathrm{mL}$ (urine) on the same day. For inter-day precision analysis, three sets of six replicate plasma or urine samples at the same concentrations as above were analyzed on three different days.

The lower limit of detection and lowest concentration at which the compounds can be confirmed were checked to find out the sensitivity of the method. Triplicate plasma samples at $2,5,10,20$, and $50 \mathrm{pg} / \mathrm{mL}$ were extracted and analyzed. Urine samples at concentrations of 10, 20, 50, 100, 200, and $500 \mathrm{pg} / \mathrm{mL}$ were also tested in triplicate.

\section{Results and Discussion}

\subsection{Method Development}

The aim of our research was to develop and validate a simple, fast, sensitive and selective LC-MS/MS method for confirmation and enantiomer separation of amphetamines and cathinones extracted from equine blood or urine. Since more than $50 \%$ of the pharmaceutical drugs are chiral, enantioselective chromatography has gained more and more attention [14] [15] [26]. There are many types of commercial chiral columns with different stationary phases [25] [27]. These stationary phases include polysaccharide derivatives, macrocyclic antibodies, proteins, cyclodextrins and pirke-type. Efficiency of enantioseparation is mainly determined by the chiral discriminative power of the chiral stationary phase employed. Macrocyclic antibody Vancomycin-based CHIROBIOTIC V2 column has demonstrated separation of amine compounds and worked well for our applications.

The separation of chiral drugs was performed under isocratic conditions. Several mobile phase modifiers were studied in order to obtain chiral separation in LC and to maintain satisfactory electrospray ionisation performance in positive ionization mode. Methanol, acetonitrile, formic acid, acetic acid, ammonium formate and ammonium acetate were tested for mobile phases or additives. Methanol, formic acid and ammonium formate were chosen because narrower chromatographic peaks with shorter retention times were achieved with this mobile phase. Also, ammonium formate and formic acid were used in this method due to their solubility in high content organic mobile phases and their volatility for fast solvent evaporation inelectrospray. High percentage of organic solvent methanol also makes solvent evaporation easier and promotes better sensitivity. Figure 1 shows the separation of the four compounds and the eight isomers showed their unique retention times. All of the analytes were eluted in 5 minutes. Even though the (S)- and (R)-enantiomers are not baseline resolved, the resolution was sufficient to unambiguously differentiate the two isomers. 


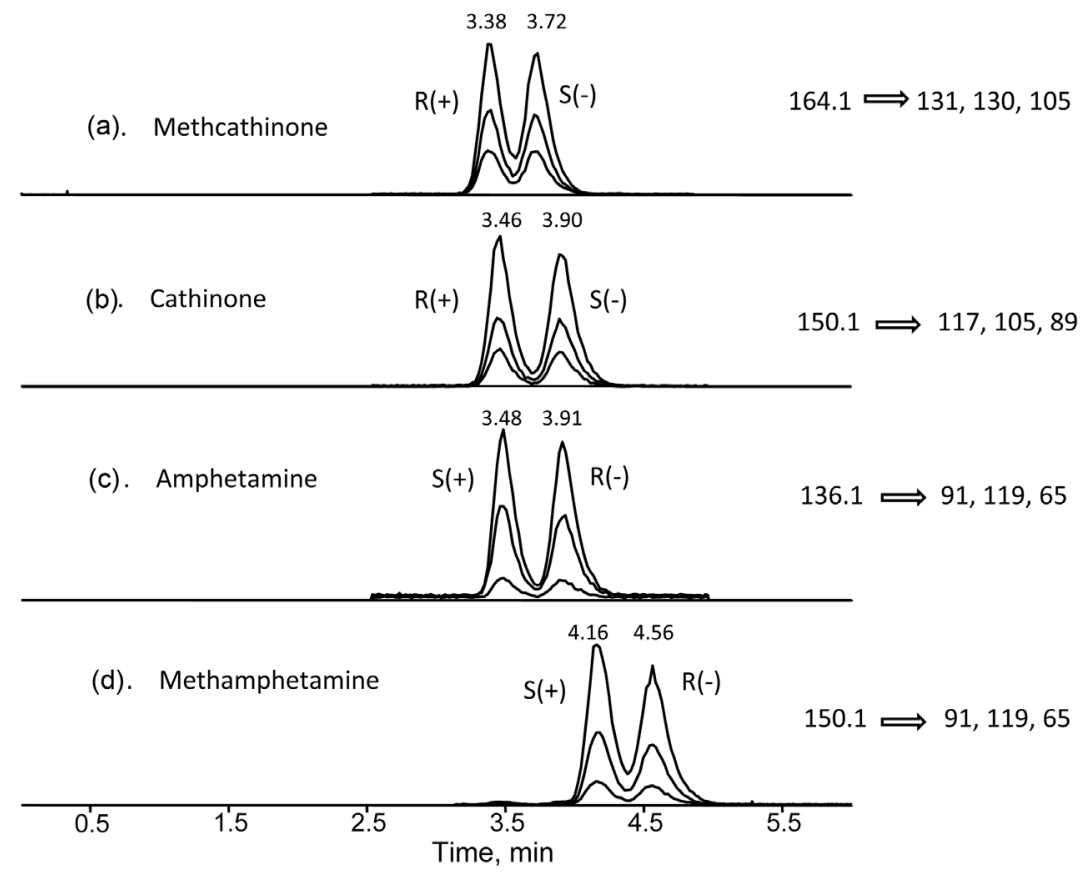

Figure 1. Chiral separation chromatograms of methcathinone, cathinone, amphetamine and methamphetamine extracted from a plasma sample spiked at $0.1 \mathrm{ng} / \mathrm{mL}$.

\subsection{Method Validation Results}

Specificity testing was performed to make sure this method was free of endogenous compounds and other matrix interferences that could potentially produce a false positive signal and interfere with the analysis. Six different lots of blank equine plasma or urine samples were analyzed and the results indicated that the method is specific, because no interference peaks, capable of producing false positives, were observed in the MRM chromatograms.

A simple one step liquid-liquid extraction was used for sample processing. MTBE has a low boiling point and it evaporates quickly. Compared to the commonly used extraction solvent ethyl acetate, plasma and urine extracted with MTBE resulted in much cleaner extract, especially under basic conditions. The extraction recovery results for equine plasma and urine are listed in Table 2. Extraction recovery in plasma ranges from 84\% to $100 \%$ and it is between $70 \%$ to $98 \%$ for urine. Urine samples had lower recovery compared to plasma. Even though cathinone has lowest extraction recovery among others (70\% for urine and $84 \%$ for plasma), the results demonstrated that most of the drugs are extracted and recovered from both sample matrices.

Co-eluting compounds may cause ion suppressions or enhancements in the electrospray ionization process. These co-eluting compounds are extracted from the sample matrix together with the analytes, resulting in stronger or weaker signal. Triplicate plasma and urine extracts were compared with water extracts, which should be free of matrix effect (100\%). In Table 2, matrix effect results showed slightly over $100 \%$ in general, which indicates both plasma and urine have some ion signal enhancements. This method is not a quantification method and the minor ion signal enhancement can be accepted.

Intra-day method precision was evaluated by analyzing six replicate plasma or urine samples on the same day. Inter-day method precision was evaluated by analyzing eighteen plasma or urine samples that were acquired on three different days. The precision of the method was determined by calculating the relative standard deviation (RSD) of peak areas of quantifying ions. The RSDs of allanalytes are below 5\%, as listed in Table 2. The low RSDs indicated that the method had good precision for routine qualitative enantiomer analysis of metham-phetamine, amphetamine, cathinone and methcathinonein equine plasma and urine.

The lower limit of detection (LLOD) of this method in both equine plasma and urine is defined as the lowest concentration at which the compound of interest could be detected but not necessarily confirmed. It can be estimated as the lowest concentration at which all MRM products ions showed a signal-to-noise ratio $\geq 3$. For medication violations, the racing industry commonly accepts confirmation criteria that include retention time and 
Table 2. Urine and plasma validation results for methamphetamine, amphetamine, cathinone and methcathinone (S)- and (R)-enantiomers.

\begin{tabular}{|c|c|c|c|c|c|c|c|c|}
\hline \multirow[t]{2}{*}{ Urine validation results } & \multicolumn{2}{|c|}{ Methamphetamine } & \multicolumn{2}{|c|}{ Amphetamine } & \multicolumn{2}{|c|}{ Cathinone } & \multicolumn{2}{|c|}{ Methcathinone } \\
\hline & $\mathrm{S}(+)$ & $\mathbf{R}(-)$ & $\mathrm{S}(+)$ & $\mathbf{R}(-)$ & $\mathbf{R}(+)$ & $\mathbf{S}(-)$ & $\mathbf{R}(+)$ & $\mathbf{S}(-)$ \\
\hline Extraction recovery & $94 \%$ & $98 \%$ & $86 \%$ & $85 \%$ & $70 \%$ & $70 \%$ & $85 \%$ & $86 \%$ \\
\hline Matrix effect & $114 \%$ & $106 \%$ & $108 \%$ & $109 \%$ & $111 \%$ & $113 \%$ & $118 \%$ & $117 \%$ \\
\hline Precision RSD (intra-day) (6) & $2.7 \%$ & $3.7 \%$ & $3.4 \%$ & $2.3 \%$ & $4.0 \%$ & $4.4 \%$ & $3.8 \%$ & $3.2 \%$ \\
\hline Precision RSD (inter-day) $(6+6+6)$ & $2.8 \%$ & $4.0 \%$ & $2.8 \%$ & $3.2 \%$ & $3.6 \%$ & $3.7 \%$ & $4.3 \%$ & $3.3 \%$ \\
\hline Lower limit of detection $(\mathrm{pg} / \mathrm{mL})$ & 20 & 20 & 200 & 200 & 250 & 250 & 20 & 20 \\
\hline Lower limit of confirmation $(\mathrm{pg} / \mathrm{mL})$ & 50 & 50 & 500 & 500 & 500 & 500 & 50 & 50 \\
\hline \multirow[t]{2}{*}{ Plasma validation results } & \multicolumn{2}{|c|}{ Methamphetamine } & \multicolumn{2}{|c|}{ Amphetamine } & \multicolumn{2}{|c|}{ Cathinone } & \multicolumn{2}{|c|}{ Methcathinone } \\
\hline & $\mathrm{S}(+)$ & $\mathbf{R}(-)$ & $\mathrm{S}(+)$ & $\mathbf{R}(-)$ & $\mathbf{R}(+)$ & $\mathbf{S}(-)$ & $\mathbf{R}(+)$ & $\mathbf{S}(-)$ \\
\hline Extraction recovery & $100 \%$ & $97 \%$ & $95 \%$ & $98 \%$ & $84 \%$ & $84 \%$ & $100 \%$ & $94 \%$ \\
\hline Matrix effect & $109 \%$ & $112 \%$ & $118 \%$ & $117 \%$ & $98 \%$ & $112 \%$ & $113 \%$ & $123 \%$ \\
\hline Precision RSD (intra-day) (6) & $3.7 \%$ & $2.2 \%$ & $4.3 \%$ & $4.7 \%$ & $3.5 \%$ & $2.9 \%$ & $3.8 \%$ & $3.7 \%$ \\
\hline Precision RSD (inter-day) $(6+6+6)$ & $4.5 \%$ & $4.6 \%$ & $4.8 \%$ & $4.6 \%$ & $3.9 \%$ & $2.9 \%$ & $4.3 \%$ & $3.2 \%$ \\
\hline Lower limit of detection $(\mathrm{pg} / \mathrm{mL})$ & 2 & 2 & 20 & 20 & 10 & 10 & 2 & 2 \\
\hline Lower limit of confirmation $(\mathrm{pg} / \mathrm{mL})$ & 5 & 5 & 50 & 50 & 25 & 25 & 5 & 5 \\
\hline
\end{tabular}

spectral match, or comparison of the chromatographic peak area ratios of MRM signals for samples, calibrators and a neat standard. The lowest concentration at which the compounds can be confirmed was taken as the concentration at which the analyte responses were identifiable and discrete with a signal to noise ratio $\geq 10$ for all MRM ionchromatogram peaks used. At this concentration, the product ion peak relative abundances should fall within the acceptable range when compared to the reference spectrum (Association of Official Racing Chemists (AORC) confirmation criteria: $10 \%$ absolute or $30 \%$ relative, whichever is greater) [28]. The results listed in Table 2 demonstrated that methamphetamine and methcathinone are more sensitive and they both could be detected as low as $2 \mathrm{pg} / \mathrm{mL}$ in plasma and $20 \mathrm{pg} / \mathrm{mL}$ in urine. In this method, urine sample volume used is only 0.1 $\mathrm{mL}$. If more urine sample is used, the LLOD could be lower even though more matrix effect may be present. Amphetamine has relatively higher LLOD because MRM transition $m / z$ 136 - 65 is not sensitive. However, a LLOD of $20 \mathrm{pg} / \mathrm{mL}$ in plasma and $200 \mathrm{pg} / \mathrm{mL}$ in urine are still the lowest numbers reported for amphetamine chiral analysis from equine samples. Overall, this method presented very good sensitivity coupled with short analysis time.

\subsection{Race-Track Sample Applications}

In the past two years, 12 equine urine samples and 6 plasms samples were confirmed positive for metham-phetamine. Only one plasma and one urine sample from the same horse were R-methamphetamine and all of the other confirmations were (S)-enantiomer. Figure 2 is an example showing an equine (S)-methamphetamine positive confirmation in both urine and plasma. It clearly demonstrated the retention time differences between the two isomers and resulted in an easy conclusion of which enantiomer is present in the samples.

\section{Conclusion}

A fast and easy method for enantiomer separation of amphetamines and cathinones was developed and validated. 
(a). Blank urine

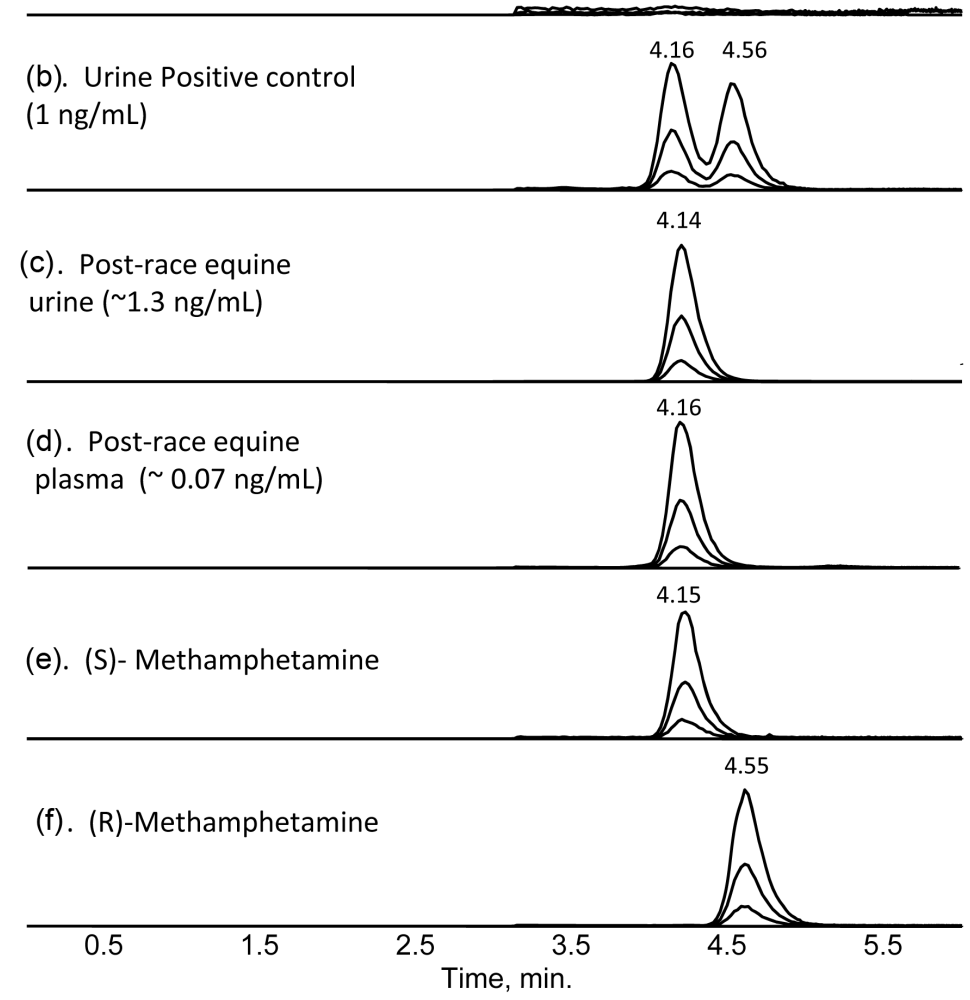

Figure 2. An example of (S)-methamphetamine identification in post-race horse urine and plasma samples. The three MRM transition traces are all shown. Product ion chromatograms of methamphetamine from analysis of (a) Blank urine; (b) Urine positive control; (c) Post-race equine urine sample; (d) The corresponding post-race equine plasma sample; (e) (S)-Methamphetamine standard; (f) (R)-Methamphetamine standard.

This method presented excellent reproducibility and sensitivity. Applicability was demonstrated by routine application of post-race equine urine and plasma samples.

\section{References}

[1] Paul, B.D. and Cole, K.A. (2001) Cathinone (Khat) and Methcathinone (CAT) in Urine Specimens: A Gas Chromatography-Mass Spectrometric Detection Procedure. Journal of Analytical Toxicology, 25, 525-530. http://dx.doi.org/10.1093/jat/25.7.525

[2] Sporkert, F., Pragst, F., Bachus, R., Masuhr, F. and Harms, L. (2003) Determination of Cathinone, Cathine and Norephedrine in Hair of Yemenite Khat Chewers. Forensic Science International, 133, 39-46. http://dx.doi.org/10.1016/S0379-0738(03)00048-3

[3] Strano-Rossi, S., Botre, F., Bermejo, A.M. and Tabernero, M.J. (2009) A Rapid Method for the Extraction, Enantiomeric Separation and Quantification of Amphetamines in Hair. Forensic Science International, 193, 95-100. http://dx.doi.org/10.1016/j.forsciint.2009.09.016

[4] Yi, R., Zhao, S., Lam, G., Sandhu, J., Loganathan, D. and Morrissey, B. (2013) Detection and Elimination Profile of Cathinone in Equine after Norephedrine (Propalin ${ }^{\circledR}$ ) Administration Using a Validated Liquid ChromatographyTandem Mass Spectrometry Method. Analytical and Bioanalytical Chemistry, 405, 9711-9722. http://dx.doi.org/10.1007/s00216-013-7073-0

[5] Mikuma, T., Iwata, Y.T., Miyaguchi, H., Kuwayama, K., Tsujikawa, K., Kanamori, T. and Inoue, H. (2015) The Use of a Sulfonated Capillary on Chiral Capillary Electrophoresis/Mass Spectrometry of Amphetamine-Type Stimulants for Methamphetamine Impurity Profiling. Forensic Science International, 249, 59-65. http://dx.doi.org/10.1016/j.forsciint.2015.01.015 
[6] Pasin, D., Bidny, S. and Fu, S. (2015) Analysis of New Designer Drugs in Post-Mortem Blood Using High-Resolution Mass Spectrometry. Journal of Analytical Toxicology, 39, 163-171. http://dx.doi.org/10.1093/jat/bku144

[7] Gambaro, V., Arnoldi, S., Colombo, M.L., Dellacqua, L., Guerrini, K. and Roda, G. (2012) Determination of the Active Principles of Catha Edulis: Quali-Quantitative Analysis of Cathinone, Cathine, and Phenylpropanolamine. Forensic Science International, 217, 87-92. http://dx.doi.org/10.1016/j.forsciint.2011.09.028

[8] Holler, J.M., Vorce, S.P., Bosy, T.Z. and Jacobs, A. (2005) Quantitative and Isomeric Determination of Amphetamine and Methamphetamine from Urine Using a Nonprotic Elution Solvent and R(-)-a-Methoxy-a-Trifluoromethylphenylacetic Acid Chloride Derivatization. Journal of Analytical Toxicology, 29, 652-657. http://dx.doi.org/10.1093/jat/29.7.652

[9] Makino, Y., Ohta, S. and Hirobe, M. (1996) Enantiomeric Separation of Amphetamine by High-Performance Liquid Chromatography Using Chiral Crown Ether-Coated Reversed-Phase Packing: Application to Forensic Analysis. Forensic Science International, 78, 65-70. http://dx.doi.org/10.1016/0379-0738(95)01865-4

[10] Glennon, R.A., Schechter, M.D. and Rosecrans, J.A. (1984) Discriminative Stimulus Properties of S(-)- and R(+)Cathinone, (+)-Cathine and Several Structural Modifications. Pharmacology Biochemistry \& Behavior, 21, 1-3. http://dx.doi.org/10.1016/0091-3057(84)90121-7

[11] Nielsen, J.A. and Schechter, M.D. (1985) Behavioral and Neurochemical Effects of (-)- and ( \pm )-Cathinone: DoseResponse and Time-Course. Progress in Neuro-Psychopharmacology and Biological Psychiatry, 9, 739-743. http://dx.doi.org/10.1016/0278-5846(85)90052-1

[12] Mohr, S., Weib, J.A., Spreitz, J. and Schmid, M.G. (2012) Chiral Separation of New Cathinone- and AmphetamineRelated Designer Drugs by Gas Chromatography-Mass Spectrometry Using Trifluoroacetyl-L-Prolyl Chloride as Chiral Derivatization Reagent. Journal of Chromatography A, 1269, 352-359. http://dx.doi.org/10.1016/j.chroma.2012.09.079

[13] Rasmssen, L.B., Olsen, K.H. and Johansen, S.S. (2006) Chiral Separation and Quantification of R/S-Amphetamine, R/S-Methamphetamine, R/S-MDA, R/S-MDMA, and R/S-MDEA in Whole Blood by GC-EI-MS. Journal of Chromatography B, 842, 136-141. http://dx.doi.org/10.1016/j.jchromb.2006.05.011

[14] Nystrom, I., Trygg, T., Woxler, P., Ahlner, J. and Kronstrand, R. (2005) Quantitation of R-(-)- and S-(+)-Amphetamine in Hair and Blood by Gas Chromatography-Mass Spectrometry: An Application to Compliance Monitoring in AdultAttention Deficit Hyperactivity Disorder Treatment. Journal of Analytical Toxicology, 29, 682-688. http://dx.doi.org/10.1093/jat/29.7.682

[15] Mislanova, C. and Hutta, M. (2003) Role of Biological Matrices during the Analysis of Chiral Drugs by Liquid Chromatography. Journal of Chromatography B, 797, 91-109. http://dx.doi.org/10.1016/j.jchromb.2003.07.018

[16] Guillarme, D., Bonvin, G., Badoud, F., Schappler, J., Rudaz, S. and Veuthey, J. (2010) Fast Chiral Separation of Drugs Using Columns Packed with Sub-2 $\mu \mathrm{m}$ Particles and Ultra-High Pressure. Chirality, 22, 320-330.

[17] Kasprzyk-Hordern, B., Kondakal, V.V.R. and Baker, D.R. (2010) Enantiomeric Analysis of Drugs of Abuse in Wastewater by Chiral Liquid Chromatography Coupled with Tandem Spectrometry. Journal of Chromatography A, 1217, 4575-4586. http://dx.doi.org/10.1016/j.chroma.2010.04.073

[18] Bagnall, J.P., Evans, S.E., Wort, M.T., Lubben, A.T. and Kasprzyk-Hordern, B. (2012) Using Chiral Liquid Chromatography Quadrupole Time-of-Flight Mass Spectrometry for the Analysis of Pharmaceuticals and Illicit Drugs in Surface and Wastewater at the Enantiomeric Level. Journal of Chromatography A, 1249, 115-129. http://dx.doi.org/10.1016/j.chroma.2012.06.012

[19] Mohr, S., Taschwer, M. and Schmid, M.G. (2012) Chiral Separation of Cathinone Derivatives Used as Recreational Drugs by HPLC-UV Using a Chiralpak AS-H Column as Stationary Phase. Chirality, 24, 486-492. http://dx.doi.org/10.1002/chir.22048

[20] Schwaninger, A.E., Meyer, W.R. and Maurer, H.H. (2012) Chiral Drug Analysis Using Mass Spectrometric Detection Relevant to Research and Practice in Clinical and Forensic Toxicology. Journal of Chromatography A, 1269, 122-135. http://dx.doi.org/10.1016/j.chroma.2012.07.045

[21] Perera, R.W.H., Abraham, I., Gupta, S., Kowalska, P., Lightsey, D., Marathaki, C., Singh, N.S. and Lough, W.J. (2012) Screening Approach, Optimization and Scale-Up for Chiral Liquid Chromatography of Cathinones. Journal of Chromatography A, 1269, 189-197. http://dx.doi.org/10.1016/j.chroma.2012.11.001

[22] Newmeyer, M.N., Concheiro, M. and Huestis, M.A. (2014) Rapid Quantitative Chiral Amphetamine Liquid Chromatography-Tandem Mass Spectrometry: Method in Plasma and Oral Fluid with a Cost-Effective Chiral Derivatizing Reagent. Journal of Chromatography A, 1358, 68-74. http://dx.doi.org/10.1016/j.chroma.2014.06.096

[23] Wang, T., Shen, B., Shi, Y., Xiang, P. and Yu, Z. (2015) Chiral Separation and Determination of R/S-Methamphetamine and Its Metabolite R/S-Amphetamine in Urine Using LC-MS/MS. Forensic Science International, 246, 72-78. http://dx.doi.org/10.1016/j.forsciint.2014.11.009 
[24] Taschwer, M., Seidi, Y., Mohr, S. and Schmid, M.G. (2014) Chiral Separation of Cathinone and Amphetamine Derivatives by HPLC/UV Using Sulfated $\beta$-Cyclodextrin as Chiral Mobile Phase Additive. Chirality, 26, 411-418. http://dx.doi.org/10.1002/chir.22341

[25] Ribeiro, A.R., Maia, A.S., Cass, Q.B. and Tiritan, M.E. (2014) Enantioseparation of Chiral Pharmaceuticals in Biomedical and Environmental Analyses by Liquid Chromatography: An Overview. Journal of Chromatography B, 968, 8-21. http://dx.doi.org/10.1016/j.jchromb.2014.02.049

[26] Nguyen, L.A., He, H. and Pham-Huy, C. (2006) Chiral Drugs: An Overview. International Journal of Biomedical Science, 2, 85-100.

[27] Hamman, C., Wong, M., Aliagas, I., Ortwine, D.F., Pease, J., Schmid, D.E. and Victorino, J. (2013) The Evaluation of 2 Chiral Stationary Phase and the Utilization of Sub-2.0 $\mu \mathrm{m}$ Coated Polysaccharide Chiral Stationary Phases via Supercritical Fluid Chromatography. Journal of Chromatography A, 1305, 310-319. http://dx.doi.org/10.1016/j.chroma.2013.07.046

[28] The Association of Official Racing Chemists (2015) AORC Guidelines for the Minimum Criteria for Identification by Chromatography and Mass Spectrometry. http://www.aorc-online.org/documents/aorc-ms-criteria-jan-2015/ 